Int. J. Electrochem. Sci., 15 (2020) $8108-8118$

\title{
Self-assembly of Amino-Functionalized MOF as Highly Dispersed Cathode Catalyst for Microbial Fuel Cells
}

Qiang Zhang ${ }^{\dagger 1,2}$, Xuedong Zhao ${ }^{\dagger 2}$, Yunhua Hou ${ }^{2}$, Xiaoliang Wang ${ }^{2}$, Wenjie Li ${ }^{2}$, Guangli Liu $^{2}$, Jingzhen Wang ${ }^{1,2, *}$, Jing Yang ${ }^{3, *}$, Qinzheng Yang ${ }^{1,2, *}$

${ }^{1}$ State Key Laboratory of Biobased Material and Green Papermaking, Qilu University of Technology, Shandong Academy of Sciences, Jinan, 250353, Shandong, P. R. China

${ }^{2}$ Department of Bioengineering, Qilu University of Technology (Shandong Academy of Sciences), Jinan 250353, Shandong, P.R. China

${ }^{3}$ School of Electronic and Information Engineering (Department of Physics), Qilu University of

Technology (Shandong Academy of Sciences), Jinan 250353, Shandong, P.R. China

${ }^{\dagger}$ Qiang Zhang and Xuedong Zhao contributed equally

*E-mail: wjz_424@163.com, yangjing.xy@163.com, yqz@qlu.edu.cn

doi: $10.20964 / 2020.08 .76$

Received: 20 December 2019 / Accepted: 1 May 2020 / Published: 10 July 2020

The uniform dispersion of the catalyst is a key factor for the preparation of high-performance microbial fuel cell (MFC) cathodes. Herein, we self-assemble the amino ligand onto the surface of the carbon cloth (CC) by a one-pot method and complex the copper ions to form an amino-functionalized copper metalorganic framework $\left(\mathrm{Cu}-\mathrm{MOF}-\mathrm{NH}_{2}\right)$ as a cathode catalyst for the MFC. The positive charge and polarity of the amino group improve the interaction between the $\mathrm{Cu}-\mathrm{MOF}-\mathrm{NH}_{2}$ and the carbon-based electrode, achieving high dispersion and high catalytic activity of the $\mathrm{Cu}-\mathrm{MOF}-\mathrm{NH}_{2}$. The application results show that the $\mathrm{Cu}-\mathrm{NOF}-\mathrm{NH}_{2}$ modified cathode provides a maximum power density of $0.64 \mathrm{Wm}^{-2}$ for the MFC, which is 3.2 times higher than that of the $\mathrm{CC}$ base cathode. This work has explored a facile preparation method for a highly dispersed non-precious metal catalyst applied to a cathode, which has certain guiding significance for the large-scale popularization and application of MFCs.

Keywords: $\mathrm{Cu}-\mathrm{MOF}-\mathrm{NH}_{2}$, Air cathode, MFC, Self-assembling, ORR

\section{FULL TEXT}

(C) 2020 The Authors. Published by ESG (www.electrochemsci.org). This article is an open access article distributed under the terms and conditions of the Creative Commons Attribution license (http://creativecommons.org/licenses/by/4.0/). 